\title{
Prematurity, a significant predictor for worse outcome in viral bronchiolitis: a comparative study in infancy
}

\author{
Noussa R. El Basha ${ }^{1 *}$, Huda Marzouk', May M. Sherif² and Amani A. El Kholy²
}

\begin{abstract}
Background: The rate of admissions to hospital with bronchiolitis has increased over the past years. The reasons for this are likely to be multifactorial including improved survival of preterm infants.

Aim: To assess the severity of viral bronchiolitis in preterm compared to term infants admitted at a tertiary hospital in Cairo, Egypt, based on the outcome.

Patients and methods: This prospective study was conducted throughout a 3-year period from September 2011 to October 2014. It included 153 infants, 74 healthy preterm, and 79 healthy term infants admitted with clinical diagnosis of bronchiolitis at a tertiary hospital in Cairo, Egypt. Bronchiolitis severity score (BSS) was recorded, and nasopharyngeal swabs were obtained from each patient at the time of presentation. Viruses were identified using reverse transcription polymerase chain reaction (RT-PCR). The clinical course and patient's outcome were recorded.

Results: This study recorded a significantly more severe BSS for preterm compared to term infants. The preterm group had an increased mean length of hospital stay and oxygen therapy and was more likely to need intensive care unit admission and mechanical ventilation (MV) compared to the term group. The mean $( \pm$ SD) BSS for infections with h-MPV, RSV, and para-influenza 3 was more significantly severe in preterm compared to term infants. Bacterial co-infection was significantly correlated with severity scoring in both groups.

Conclusion: Prematurity significantly affects the severity of bronchiolitis, and this underscores the importance of early categorization as a high-risk group on their first visit. The physician should be aware that their illness runs a more severe course, even if they have no underlying disorders.
\end{abstract}

Keywords: Bronchiolitis, Viruses, Preterm, Severity

\section{Introduction}

Bronchiolitis is the most common lower respiratory tract infection in children less than 1 year of age and is usually of viral etiology [1]. Human respiratory syncytial virus (RSV) is the most commonly causing virus and identified in $60-70 \%$ of hospitalized infant with bronchiolitis [2]. Bronchiolitis by itself accounts for the greatest number of hospitalization in infancy during the fall and winter season [3].

Bronchiolitis is a self-limiting condition but may be life threating causing significant severe illness [4-6],

\footnotetext{
* Correspondence: noussaelbasha3@yahoo.com

1 Department of Pediatrics, Faculty of Medicine, Cairo University, 2 Atteia Abd El Hadi St., El Maadi, Cairo 11562, Egypt

Full list of author information is available at the end of the article
}

and it is the most common cause of hospital admission for infant beyond the neonatal period with rate varying between 1 and $3 \%$. Furthermore, approximately $10 \%$ of hospitalized infants will need intensive care admission [7-10].

The rate of admissions to hospital with bronchiolitis has increased over the past 10 years. The reasons for this are not fully understood and are likely to be multifactorial and include improved survival of preterm infants [11].

Epidemiological evidence revealed that young age (less than 6-12 weeks) and premature birth (less than 37 weeks) are associated with high risk of severe bronchiolitis $[7,12,13]$. 
The aim of the present study was to assess the severity of viral bronchiolitis in healthy preterm compared to healthy term infants in terms of the duration of hospital stay, oxygen saturation and duration of oxygen requirement, and ICU and/or MV requirement.

\section{Materials and methods}

\subsection{Study design and subjects}

This prospective study was conducted throughout a 3-year period from September 2011 to October 2014. It included 153 infants in the first year of life with clinical diagnosis of bronchiolitis, according to American Academy of Pediatrics [14], and all were admitted to inpatient departments at the Cairo University Specialized Pediatric Hospital. Seventy-four of those infants were healthy preterm (less than 37 weeks) and 79 infants were healthy term. The following specific groups were excluded: neonates, recurrent wheeze, and association of underlying chronic diseases.

\subsection{Ethical considerations}

This study was approved by the Cairo University Clinical Research Ethics Committee, and informed verbal consents were obtained from parents of the included children. The study design conformed to the Revised Helsinki Declaration of Bioethics.

\section{Methods}

All patients were subjected to thorough history taking, including demographic data, and also, full physical examination was performed with emphasis on signs of respiratory tract infection. The respiratory severity score that has been used in this study is the modified Tal score. This score ranges from 0 to 12 , with a higher score indicating more severe disease. Each score is an aggregate of assigned values ranging from 0 to 3 in categories of respiratory rate, retractions, wheezing, and oxygen saturation in room air [15]. Bronchiolitis severity score (BSS) was recorded for each patient at the time of presentation. Subsequently, during inpatient management, the following data were recorded: the clinical course was observed during the hospital stay including the need for intensive care unit (ICU) admission, need for mechanical ventilation (MV), duration of oxygen therapy, and duration of hospital stay.

\subsection{Clinical specimens}

Complete blood count $(\mathrm{CBC})$ and $\mathrm{C}$-reactive protein (CRP) were determined at the time of study enrollment for each patient. Oropharyngeal (OP) and nasopharyngeal (NP) swabs were obtained for PCR at the time of presentation and put in viral transport media (VTM).

\subsection{Molecular identification of respiratory viruses}

Total nucleic acid (TNA) was extracted from the NP/OP swabs by the automated KingFisher Flex Magnetic Particle Processor (Thermo Scientific, Waltham, USA) using MagMAX Total Nucleic Acid Isolation Kit (Cat No. AM 1840, Applied Biosystems, Foster City, USA) according to the manufacturer's instructions. All the viral targets were amplified using specific primers and probes produced by the Center of Disease Control and Prevention (CDC), Atlanta, USA, and following standard protocol for quantitative reverse transcription PCR detection.

Detection of influenza viruses was conducted in the Cairo University Hospital laboratory and confirmed by the Naval Medical Research Unit No.3 (NAMRU-3) laboratory. The samples were screened for the presence of influenza $A$ and B using the CDC kit for influenza following CDC protocol [16]. Samples positive for influenza A were further subtyped according to the CDC protocol to the following types: pandemic influenza 2009 $\mathrm{A}(\mathrm{H} 1 \mathrm{~N} 1)$ and seasonal $\mathrm{H} 1$ and $\mathrm{H} 3$.

Testing for adenovirus; human parainfluenza viruses 1 , 2 , and 3 (hPIV); respiratory syncytial virus (RSV); and human metapneumovirus (hMPV) was done at NAMRU-3 laboratory by RT-qPCR using CDC specific primers and probes and following a CDC protocol for the detection of non-influenza viruses. Samples were considered positive to the viral target if the amplification curve crossed the threshold line before cycle 40. All clinical samples had to be positive for the human RNAse P gene (RP), with a $C t$ value $\leq 37$, for validation. A positive control for each virus was added to each run to ensure adequate amplification of the target genes.

\subsection{Statistical analysis}

Precoded data was entered on the Statistical Package of Social Science Software program, version 23 (IBM SPSS Statistics for Windows, Version 23.0. Armonk, NY, IBM Corp.) to be statistically analyzed. Data was presented using mean and standard deviation for quantitative variables and frequency and percentage for qualitative ones. Comparison between groups was performed using independent sample $t$ test or Mann-Whitney for quantitative variables and chi-square and Fisher's exact test for qualitative ones. Spearman correlation coefficient was used to estimate the association between different quantitative variables. $P$ values less than 0.05 were considered statistically significant.

\section{Results}

The study included 153 infants with a clinical diagnosis of acute bronchiolitis in otherwise healthy infants. Seventy-nine of them were term and 74 were preterm infants. The detailed demographic characteristics including risk factors for bronchiolitis of both preterm 
Table 1 Demographic characteristics of preterm and term infants with bronchiolitis, Cairo University Specialized Pediatric Hospital

\begin{tabular}{llll}
\hline Variables & $\begin{array}{l}\text { Preterm infants } \\
(n=74)\end{array}$ & $\begin{array}{l}\text { Term infants } \\
(n=79)\end{array}$ & ${ }^{*} P$ value \\
\hline Age in months (mean \pm SD) & $5.2 \pm 4.1$ & $7 \pm 4.2$ & 0.001 \\
Sex & $36(48.6 \%)$ & $41(51.9 \%)$ & 0.747 \\
$\quad$ Male & $38(51.4 \%)$ & $38(48.1 \%)$ & \\
$\quad$ Female & $46(62.2 \%)$ & $41(51.9 \%)$ & 0.253 \\
History of passive smoking & $32(43.2 \%)$ & $27(34.2 \%)$ & 0.319 \\
\hline Non-exclusive breast feeding & & & \\
\hline
\end{tabular}

${ }^{*} P$ value $>0.05$ is statistically insignificant

and term infants are summarized in Table 1. Preterm infants were significantly younger than term infants $(P$ value 0.001$)$.

Clinical findings at the time of presentation, BSS, and outcomes of both groups are shown in Table 2. BSS (Mean \pm SD) was significantly more severe for preterm compared to term infants at time of presentation $(P$ value 0.045$)$. Also, preterm group had an increased mean length of hospital stay, and mean duration of oxygen therapy compared to term group $(P$ value 0.002 and 0.001 , respectively). Preterm infants were significantly more likely to need ICU admission ( $P$ value 0.007$)$ and MV ( $P$ value 0.033$)$ than term infants.

Viral screening results are summarized in Table 3. Respiratory viruses were detected in 36 (48.6\%) preterm patients and in $53(67 \%)$ term patients with acute bronchiolitis. RSV was the most commonly detected virus in both groups, although, more significantly frequent in term infants $(57 \%)$ than preterm infants $(32.4 \%)$ ( $P$ value 0.003$)$. On the other hand, adenovirus was more significantly frequent in preterm than term infants $(16.2 \%$ and $5.1 \%$; respectively, $P$ value 0.033 ). Concomitantly with the viral respiratory infection, preterm patients had more frequent concomitant bacterial infections than term despite non-significance ( $P$ value 0.221 ).

On comparing BSS of different viral agents in preterm and term infants, the mean $( \pm \mathrm{SD})$ score for $\mathrm{h}-\mathrm{MPV}$, RSV, and para-influenza 3 was more significantly severe in preterm compared to term infants ( $P$ value 0.003 , 0.009 , and 0.013, respectively), as shown in Table 4.

On correlating bronchiolitis severity score to screened viruses and outcome in both groups mixed viral infection did not correlate with severity scoring of bronchiolitis in preterm and term groups $(P$ value. $0.723,0.537$, respectively). However, bacterial co-infection was significantly

Table 2 Clinical findings on presentation and outcomes of the preterm and the term infants with bronchiolitis

\begin{tabular}{|c|c|c|c|}
\hline Variables & $\begin{array}{l}\text { Preterm infants } \\
N(\%)\end{array}$ & $\begin{array}{l}\text { Term infants } \\
N(\%)\end{array}$ & *P value \\
\hline Respiratory rate (mean $\pm \mathrm{SD}$ ) & $54.7 \pm 10.2$ & $47.8 \pm 10.5$ & $<0.001$ \\
\hline \multicolumn{4}{|l|}{ Respiratory distress (RD) } \\
\hline No RD & $10(13.51)$ & $28(35.4)$ & 0.003 \\
\hline Grade 1 & $10(13.51)$ & $12(15.2)$ & 0.821 \\
\hline Grade 2 & $16(21.62)$ & $13(16.5)$ & 0.536 \\
\hline Grade 3 & $30(40.55)$ & $24(30.4)$ & 0.236 \\
\hline Grade 4 & $8(10.81)$ & $2(2.5)$ & 0.051 \\
\hline Lethargy & $28(37.8)$ & $9(11.4)$ & $<0.001$ \\
\hline No drink & $34(45.9)$ & $46(58.2)$ & 0.147 \\
\hline Seizures & $4(5.4)$ & $2(2.5)$ & 0.431 \\
\hline Vomiting & $16(21.6)$ & $36(45.6)$ & 0.002 \\
\hline Oxygen saturation (mean \pm SD) & $85.4 \pm 13.1$ & $90.6 \pm 9.7$ & 0.016 \\
\hline Duration of oxygen therapy (mean \pm SD) & $4.4 \pm 1.7$ & $2.9 \pm 1.4$ & 0.001 \\
\hline PICU admission & $18(24.3)$ & $6(7.6)$ & 0.007 \\
\hline Duration of PICU admission (mean \pm SD) & $3.8 \pm 1.3$ & $3.2 \pm 0.4$ & 0.186 \\
\hline Mechanical ventilation (MV) & $12(16.2)$ & $4(5.1)$ & 0.003 \\
\hline Duration of MV (mean \pm SD) & $3.3 \pm 1.0$ & $2.5 \pm 1.0$ & 0.128 \\
\hline Duration of hospital stay (mean \pm SD) & $5.4 \pm 1.6$ & $4.0 \pm 1.6$ & 0.002 \\
\hline \multicolumn{4}{|l|}{ Bronchiolitis severity score (BSS) } \\
\hline Mean \pm SD & $9.6 \pm 3.8$ & $8.3 \pm 3.3$ & 0.045 \\
\hline Severe bronchiolitis & $36(48.6 \%)$ & $26(32.9 \%)$ & 0.051 \\
\hline
\end{tabular}

${ }^{*} P$ values $<0.05$ is statistically significant 
Table 3 Viral PCR results among preterm and term infants with bronchiolitis

\begin{tabular}{llll}
\hline Viruses & $\begin{array}{l}\text { Viral positive in preterm infants } \\
n=36\end{array}$ & $\begin{array}{l}\text { Viral positive in term infants } \\
n=53 \\
N(\%)\end{array}$ & $\begin{array}{c}* \\
*\end{array}$ \\
\hline RSV value \\
Adenovirus & $24(32.4)$ & $45(57)$ & $4(5.1)$ \\
h-MPV & $12(16.2)$ & $1(1.3)$ & 0.003 \\
Influenza A & $4(5.4)$ & $2(2.5)$ & 0.033 \\
Influenza B & $8(10.8)$ & $0(0.0)$ & 0.198 \\
Para-influenza 1 & $0(0.0)$ & $0(0.0)$ & - \\
Para-influenza 3 & $0(0.0)$ & $6(7.6)$ & -051 \\
Mixed viral infection & $2(2.7)$ & $5(6.3)$ & 0.278 \\
Co-infection with bacterial & $12(16.2)$ & $7(8.9)$ & 0.071 \\
\hline
\end{tabular}

${ }^{*} P$ values $<0.05$ is statistically significant

correlated with severity scoring in both groups $(P$ value $<$ 0.001). Also, we found significant correlation between BSS and need for admission. Also, there was significant correlation between severity and duration of hospital stay and oxygen therapy as are shown in Table 5.

\section{Discussion}

We identified a viral etiology in $48.6 \%$ of preterm infants and in $67 \%$ of term infants hospitalized with acute bronchiolitis; one or more viral pathogens were detected. RSV was the most frequently isolated respiratory virus in both preterm and term infants with bronchiolitis, and adenovirus was the second most frequently detected virus in the current study. The predominance of RSV is in concordance with the assertion that this virus is the single most frequently identified lower respiratory tract pathogen in hospitalized infants worldwide [17-20]. Although, RSV significantly affects more term infant in this study, yet it is likely to be associated with more severe disease in preterm infants, this observation is important in planning protocols for bronchiolitis prophylaxis and management in such high-risk preterm infants. Similarly, h-MPV and para-influenza 3 infections were more severe in preterm than term infants. So, physicians treating preterm infants with RSV, h-MPV, and para-influenza 3

Table 4 Correlation between screened viruses and bronchiolitis severity score (BSS) in preterm and term infants

\begin{tabular}{llll}
\hline Outcome & \multicolumn{2}{l}{$\begin{array}{l}\text { Bronchiolitis severity score } \\
\text { (mean } \pm \text { SD) }\end{array}$} & \\
\cline { 2 - 4 } Virus & Preterm & Term & ${ }^{*}$ v value \\
\hline RSV & $9.7 \pm 3.9$ & $7.4 \pm 3.1$ & 0.009 \\
Adenovirus & $9.5 \pm 4.0$ & $10.3 \pm 2.6$ & 0.717 \\
h-MPV & $11.0 \pm 1.2$ & $5 \pm 0.0$ & 0.003 \\
Influenza A & $10.0 \pm 3.4$ & $13.5 \pm 2.1$ & 0.212 \\
Para-influenza 3 & $13.0 \pm 0.0$ & $6.7 \pm 2.4$ & 0.013 \\
\hline
\end{tabular}

${ }^{*} P$ values $<0.05$ is statistically significant bronchiolitis should be aware that their illness is more protracted and runs a more severe course than term infants, even if otherwise healthy.

The low prevalence of virus detection among preterm compared to term infants with acute bronchiolitis in this study could be attributed to other respiratory viruses which were not included in this study such as coronaviruses, bocaviruses, and rhinoviruses, and may be also explained by the fact that only patients admitted with severe infections were included in our study.

Although there were no significant differences in the length of stay in PICU and the duration of MV among preterm and term, these preterm patients had more frequent need to be managed in PICU, more frequent need for $\mathrm{MV}$, and more prolonged oxygen therapy and hospital stay than term ones. These findings were in consistence with the study by Howidi et al. [21]. These differences may be explained by smaller airway and/or suboptimal immune response in preterm infants. In addition, the significant difference in age between the two groups could partly explain the higher severity among preterm group.

We found also significant correlation between bronchiolitis severity scoring and need of hospital admission, the same as for the duration of hospital stay and duration of oxygen therapy. This was similar to results reported by Ricart et al. [22] who found that severe bronchiolitis had more mean of hospital stay compared to non-severe and more prolonged duration of oxygen and MV. We documented that preterm infants have a more severe form of illness than term infants where we found that prematurity significantly affects the severity score of bronchiolitis. Increased illness severity in infants who had bronchiolitis was discussed in several researches $[1,23]$. In this study, we found that preterm infants were significantly younger than those born term, similar to that reported by Fleming et al. [1]. 
Table 5 Correlating bronchiolitis severity score to screened viruses and outcome in preterm and term infants

\begin{tabular}{|c|c|c|c|c|}
\hline Variable & BSS in preterm & $P$ value & BSS in term & $P$ value \\
\hline \multicolumn{5}{|l|}{ Screened virus (mean \pm SD) } \\
\hline h-MPV & $11 \pm 1.2$ & 0.721 & $5 \pm 3.3$ & 0.329 \\
\hline RSV & $9.7 \pm 3.9$ & 0.676 & $7.4 \pm 3.1$ & 0.015 \\
\hline Adenovirus & $9.5 \pm 4$ & 0.953 & $10.3 \pm 2.6$ & 0.233 \\
\hline Para-influenza 3 & $13 \pm 00$ & 0.214 & $6.7 \pm 2.4$ & 0.189 \\
\hline Influenza A & $10 \pm 3.4$ & 0.7 & $13.5 \pm 2.1$ & 0.042 \\
\hline Mixed viral infection & $9.8 \pm 3.6$ & 0.723 & $9.2 \pm 3.8$ & 0.537 \\
\hline Co-infection with bacterial & $13.7 \pm 1.0$ & $<0.001$ & $13.7 \pm 2.0$ & $<0.001$ \\
\hline \multicolumn{5}{|l|}{ Outcome $(r)^{a}$} \\
\hline Duration of oxygen therapy & 0.653 & $<0.001$ & 0.721 & $<0.001$ \\
\hline Duration of hospital stay & 0.644 & $<0.001$ & 0.803 & $<0.001$ \\
\hline Duration of PICU admission & 0.304 & 0.220 & 0.310 & 0.550 \\
\hline
\end{tabular}

$P$ value $>0.05$ is statistically insignificant

BSS bronchiolitis severity score

${ }^{a}(r)$ is coefficient correlation

Mixed viral infection and bacterial co-infection in the present study were more frequently observed in preterm compared to term infants with acute bronchiolitis. However, bacterial co-infection was significantly correlated with severity scoring, while mixed viral infection did not correlate with severity scoring of bronchiolitis, and this was in consistence with what was reported by others $[22,24,25]$. This indicates that infection with multiple viruses in infants is a common situation that does not change the clinical course of bronchiolitis. However, some studies have reported an increased risk for severe bronchiolitis in dual viral infection [26-28] or even in some specific viral infections such as RSV and h-MPV co-infection [29-31].

Although respiratory viruses seem to be related to increased risk of severe disease, our data suggest that prematurity have more specific weight in predicting bronchiolitis outcome. So, understanding host susceptibility and immune response of preterm infants to these viruses, as well as targeting the prevention of infection with these viruses in preterm infant, may have even broader implications than only focusing on their role in disease morbidity.

\subsection{Limitations of the study}

Limiting this study is a possible underestimation of viral etiologies of acute bronchiolitis because testing for rhinoviruses, coronaviruses, and other viruses was not done, and these viruses were previously detected in such patients [32-35]. Also, the enrolled patients were from a single tertiary institution which is a referral center for many local hospitals, so enrolled cases may be more ill than those at other hospitals. The enrolled patients were inpatients only, while patients with mild respiratory symptoms did not undergo diagnostic testing for viral infections; they were treated in outpatient clinics and this could further direct results towards a more severe population and could influence the scores.

\section{Conclusion and recommendations}

Prematurity is one of the risk factors that significantly affect the bronchiolitis severity, and this underscores the importance of early categorization of these infants as a high-risk group on their first visit. Physicians treating preterm infants with bronchiolitis should be aware that their illness runs a more severe course than term infant, even if they have no underlying disorders.

Acknowledgments

Authors would acknowledge all patients included in this study.

Funding

This research did not receive any specific grant from funding agencies in the public, commercial, or not-for-profit sectors.

Availability of data and materials

Not applicable

Authors' contributions

NREB and HM have conducted, analyzed, and drafted the manuscript of this study. MMS and AAEK have performed the laboratory workup. All authors read and approved the final manuscript.

Ethics approval and consent to participate

This study was approved by Cairo University Clinical Research Ethics Committee, and informed verbal consents were obtained from parents of the included children. Informed verbal consent has been obtained because most of our patient guardian's are uncomfortable with reading and writing and may be too embarrassed by the written consent process to participate in a research. This informed verbal consent has been approved by Cairo University Clinical Research Ethics Committee as it covers the basic elements of the consent process that include full disclosure of the nature of the research, adequate comprehension on the part of the potential participant, and the participant's voluntary 
choice to participate. The study design conformed to the Revised Helsinki Declaration of Bioethics.

\section{Consent for publication}

Not applicable

\section{Competing interests}

The authors declare that they have no competing interests.

\section{Publisher's Note}

Springer Nature remains neutral with regard to jurisdictional claims in published maps and institutional affiliations.

\section{Author details}

${ }^{1}$ Department of Pediatrics, Faculty of Medicine, Cairo University, 2 Atteia Abd El Hadi St., El Maadi, Cairo 11562, Egypt. '2Department of Clinical Pathology, Faculty of Medicine, Cairo University, 2 Atteia Abd El Hadi St., El Maadi, Cairo 11562, Egypt.

\section{Received: 8 February 2019 Accepted: 28 February 2019}

Published online: 22 March 2019

\section{References}

1. Fleming PF, Richard S, Waterman K, Davis PG, Kamlin CO, Stewart M, et al. Medical retrieval and needs of infants with bronchiolitis: an analysis by gestational age. J Paediatr Child Health. 2013:49:E227-31.

2. Calvo C, Pozo F, Garcia-Garcia ML, Sanchez M, Lopez-Valero M, Pèrez-Breňa $P$, et al. Detection of new respiratory viruses in hospitalized infants with bronchiolitis: a three-year prospective study. Acta Pediatr. 2010;99:883-7, https://www.ncbi.nlm.nih.gov/pubmed/20163373.

3. Leader S, Kohlhase K. Respiratory syncytial virus coded pediatric hospitalizations, 1997 to 1999. Pediatr Infect Dis J. 2002;21:629-32.

4. Bialy L, Foisy M, Smith M, Fernandes RM. The Cochrane Library and the treatment of bronchiolitis in children: an overview of reviews. Evid Based Child Health. 2011;6:258-75.

5. Che D, Nicolau J, Bergounioux J, Perez T, Bitar D. Bronchiolitis among infants under 1 year of age in France: epidemiology and factors associated with mortality. Arch Pediatr. 2012;19(7):700-6.

6. Zorc JJ, Hall CB. Bronchiolitis: recent evidence on diagnosis and management. Pediatrics. 2010;125(2):342-9.

7. Deshpande SA, Northern V. The clinical and health economic burden of respiratory syncytial virus disease among children under 2 years of age in a defined geographical area. Arch Dis Child. 2003;88(12):1065-9.

8. Willson DF, Landrigan CP, Horn SD, Smout RJ. Complications in infants hospitalized for bronchiolitis or respiratory syncytial virus pneumonia. J Pediatr. 2003;143:S142-9.

9. Simoes EA, Carbonell-Estrany X. Impact of severe disease caused by respiratory syncytial virus in children living in developed countries. Pediatr Infect Dis J. 2003:22:513-8

10. Fitzgerald DA. Viral bronchiolitis for children. J Pediatr Child Health. 2011;47: 160-6.

11. Bradley JP, Bacharier LB, Bonfiglio J, Schechtman KB, Strunk R, Storch G, et al. Severity of respiratory syncytial virus bronchiolitis is affected by cigarette smoke exposure and atopy. Pediatrics. 2005;115(1):e7-e14

12. Sala KA, Moore A, Desai $\mathrm{S}$, Welch K, Bhandari $\mathrm{S}$, Carroll CL. Factors associated with disease severity in children with bronchiolitis. J Asthma. 2015:52(3):268-72

13. Chan PW, Lok FY, Khatijah SB. Risk factors for hypoxemia and respiratory failure in respiratory syncytial virus bronchiolitis. Southeast Asian J Trop Med Public Health. 2002:33:806-10.

14. American Academy of Pediatrics subcommittee on diagnosis and management of bronchiolitis. Pediatrics. 2006;118:1774-93.

15. McCallum GB, Morris PS, Wilson CC, Versteegh LA, Ward LM, Chatfield MD, et al. Severity scoring systems: are they internally valid, reliable and predictive of oxygen use in children with acute bronchiolitis? Pediatr Pulmonol. 2013:48(8):797-803.

16. World Health Organization. Information for molecular diagnosis of influenza virus in humans-update. Geneva: WHO; 2010. Accessed Jan 2010. Updated August 2011. Available: from: http://www.who.int/ influenza/resources/documents/molecular_diagnosis_influenza_virus_ humans_update_201108.pdf
17. Arden KE, McErlean P, Nissen MD, Sloots TP, Mackay IM. Frequent detection of human rhinoviruses, paramyxoviruses, coronaviruses, and bocavirus during acute respiratory tract infections. J Med Virol. 2006;78:1232-40.

18. Wong S, Pabbaraju K, Pang XL, Lee BE, Fox JD. Detection of a broad range of human adenoviruses in respiratory tract samples using a sensitive multiplex real time PCR assay. J Med Virol. 2008;80:856-65.

19. Rodríguez C, José A, Daszenies C, García M, Meyer R, Gonzales R. Adenovirus pneumonia in infants and factors for developing bronchiolitis obliterans: a 5-year follow-up. Pediatr Pulmonol. 2006:41:947-53.

20. Hall CB, Weinberg GA, Iwane MK, Blumkin AK, Edwards KM, Staat MA, et al. The burden of respiratory syncytial virus infection in young children. $\mathrm{N}$ Engl J Med. 2009;360:588-98.

21. Howidi M, Rajah J, Abushrar Z, Parsons H. The severity of respiratory syncytial virus bronchiolitis in young infants in the United Arab Emirates. Trop Pediatr. 2007;53:22-6.

22. Ricart S, Marcos MA, Sarda M, Anton A, Muñoz-Almagro C, Pumarola T. Clinical risk factors are more relevant than respiratory viruses in predicting bronchiolitis severity. Pediatr Pulmonol. 2013;48:456-63.

23. Zar HJ, Madhi SA, White DA, Masekela R, Risenga S, Lewis H, et al. Acute viral bronchiolitis in South Africa: strategies for management and prevention. S Afr Med J. 2016;106(4):27-9.

24. Wilkesmann A, Schildgen O, Eis-Hubinger AM, Geikowski T, Glatzel T, Lentze MJ, et al. Human metapneumovirus infections cause similar symptoms and clinical severity as respiratory syncytial virus infections. Eur J Pediatr. 2006; 165:467-75

25. Garcia-Garcia ML, Calvo C, Perez-Brena P, De Cea JM, Acosta B, Casas Prevalence and clinical characteristics of human metapneumovirus infections in hospitalized infants in Spain. Pediatr Pulmonol. 2006:41:863-71.

26. Midulla F, Scagnolari C, Bonci E, Pierangeli A, Antonelli G, De Angelis D, et al. Respiratory syncytial virus, human bocavirus and rhinovirus bronchiolitis in infants. Arch Dis Child. 2010:95:35-41.

27. McNamara PS, Flanagan BF, Smyth RL, Hart CA. Impact of human metapneumovirus and respiratory syncytial virus co-infection in severe bronchiolitis. Pediatr Pulmonol. 2007;42:740-3.

28. Richard N, Komurian-Pradel F, Javouhey E, Perret M, Rajoharison A, Bagnaud A, et al. The impact of dual viral infection in infants admitted to a pediatric intensive care unit associated with severe bronchiolitis. Pediatr Infect Dis J. 2008;27:213-7.

29. Semple MG, Cowell A, Dove W, Greensill J, McNamara PS, Halfhide C, et al. Dual infection of infants by human metapneumovirus and human respiratory syncytial virus is strongly associated with severe bronchiolitis. J Infect Dis. 2005:191:382-6.

30. Foulongne V, Guyon G, Rodiere M, Segondy M. Human metapneumovirus infection in young children hospitalized with respiratory tract disease. Pediatr Infect Dis J. 2006;25:354-9.

31. Greensill J, McNamara PS, Dove W, Flanagan B, Smyth RL, Hart CA. Human metapneumovirus in severe respiratory syncytialvirus bronchiolitis. Emerg Infect Dis. 2003:9:372-5.

32. Weiss SR, Navas-Martin S. Coronavirus pathogenesis and the emerging pathogen severe acute respiratory syndrome coronavirus. Microbiol Mol Biol Rev. 2005;69:635-64

33. Allander T, Jartti T, Gupta S, Niesters HG, Lehtinen P, Üsterback R, et al. Human bocavirus and acute wheezing in children. Clin Infect Dis. 2007;44: 904-10

34. Jacques J, Moret $\mathrm{H}$, Minette $\mathrm{D}$, Leveque $\mathrm{N}$, Jovenin $\mathrm{N}$, Deslée $\mathrm{G}$, et al. Epidemiological, molecular, and clinical features of enterovirus respiratory infections in French children between 1999 and 2005. J Clin Microbiol. 2008;46:206-13

35. Sloots TP, Whiley DM, Lambert SB, Nissen MD. Emerging respiratory agents: new viruses for old diseases? J Clin Virol. 2008;42:233-43. 